\title{
PRELIMINARY TESTS ON AN ENERGY ABSORBING ELEMENT FOR BRACED STRUCTURES UNDER EARTHQUAKE LOADING
}

\author{
R.G. Tyler*
}

SYNOPSIS:

While quite slender cross bracing may suffice to maintain rigidity in a braced structure under static loading conditions, during an earthquake progressive slackness develops in the bracings, resulting from overstrain in tension, which gives rise to increasing horizontal movements and degradation. In this paper tests are described on devices, fabricated from round bars and located at the centre of the bracings, which allow repetitive overstrain to occur without the development of slack. It is postulated that, for a stable condition of cyclic overstrain, the device shall be of the same shape as the frame to be braced, and most usually fabricated in steel rod or bar. Successful tests were carried out on such a device in a square frame.

\section{INTRODUCTION}

Cross bracings are often employed in structures to resist in-plane shear forces. This has the particular advantage that, during load reversals, one member of a pair of cross bracings will always be in tension, thus allowing compression buckling to be ignored. Thus the bracings will often consist of quite slender steel bars. Sometimes a ring made of steel of rectangular cross section will be used at the centre of the braces (Fig. 1), as this allows adjustment of the bracing lengths to achieve the desired geometry. The ring could behave as an energy absorbing element, although for the usual design, with a ring of flat strip pierced to take the rods, it could have a short fatique life.

While the usual design of cross bracings behaves satisfactorily under predictable loading conditions, during earthquakes severe cyclic loading will produce progressive overstrain in tension, which results in the development of slack. Under these conditions, energy absorption only occurs at the extremes of tfavel as further overstrain develops ${ }^{1}$. In contrast, the devices which were the subject of the tests described in this paper, promote a stable condition of cyclic overstrain.

A device of rectangular shape (Fig. 2) was first suggested by consulting engineers David Smith and Robert Henry of Auckland as a means of achieving energy absorption in a rectangular frame by overstain in bending at points $\mathrm{a} b \mathrm{c}$ and $\mathrm{d}$. Under dynamic loading the device distorts first to a parallelogram in one direction, and then in the other, and so on. Smith and Henry carried out static tests on two prototypes, one of which was used in a building construction. In general it was stipulated that the devices should be geometrically similar to the framework in which they were incorporated as the two parts of each diagonal are then co-linear. Because of their potential usefulness in structures such as towers the author decided to carry out tests at the Physics and Engineering Laboratory to prove stability under earthquake loading, as the

*Physics and Engineering Laboratory, DSIR, Lower Hutt, New Zealand.

BULLETIN OF THE NEW ZEALAND NATIONAL SOCIETY FOR EARTHOUAKE ENGINEERING, VOL, 16, NO, 3, SEPTEMBER 1983 devices would be required to withstand rapid stress reversals.

Referring to the rectangular frame illustrated in Fig. 2, the diagonal members are held by single nuts on the inside of the inner frame, as shown for the square frame tested in Fig. 8, so that it is not possible for compression to develop in the diagonals. On application of the force Q, Fig. 2, tension develops in diagonal BD, and deformation of the inner frame causes the diagonal length ac to shorten more than the overall distance $A C$ on the main frame, with the result that diagonal AC also goes into tension, producing self-straining forces which cause additional load at the jack in excess of that required to cause overstrain at points $\mathrm{a} b \mathrm{c}$ and $\mathrm{d}$. At the same time the shortening of diagonal ac requires an increasing force in diagonal $\mathrm{BD}$ to continue the plastic yielding at points $\mathrm{a} b \mathrm{c}$ and $\mathrm{d}$, which again throws additional load on the jack. As the inner frame is severely deformed, both effects call for large increases in the jacking load giving a resistance similar to a snubbing action. The two effects are considered in detail, for the square frame tested, in Appendix 2.

A device of this type will only perform satisfactorily where the bracings are loaded by dynamic horizontal forces oscillating about zero load. Should there be a permanent dead loading will be to cause a steady movement in one direction on overstrain and a consequent locking up of the device in that direction. With no dead load forces present the device can finish up with a permanent set following an earthquake, as can by jacking back to a central position. If the frame, without bracing, resists some horizontal loads, this resistance will provide a centering force for the braced structure and minimize permanent set.

\section{TESTS ON A RING DEVICE}

\subsection{Test details} While it was thought that a ring type
would probably suffer from the disadvantage component then the effect of an earthquake any structure, and this can be taken out 


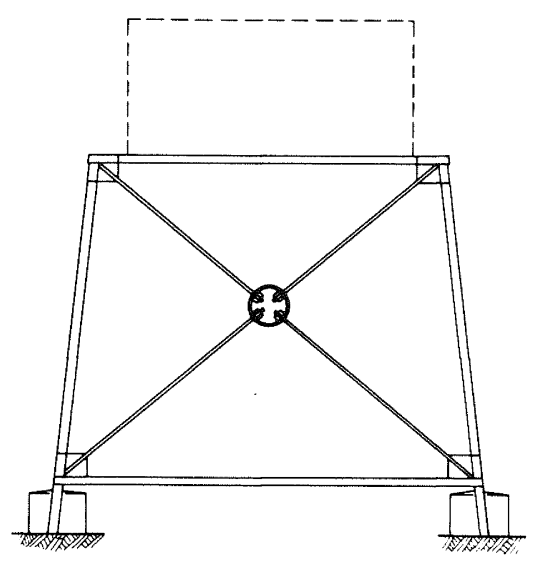

Fig. 1

Use of a ring to achieve

length adjustment in a

framed structure.

Fig. 4 (right)

Primary loading of a

circular ring device.

Fig. 2 (below)

Deformation of

rectangular device.
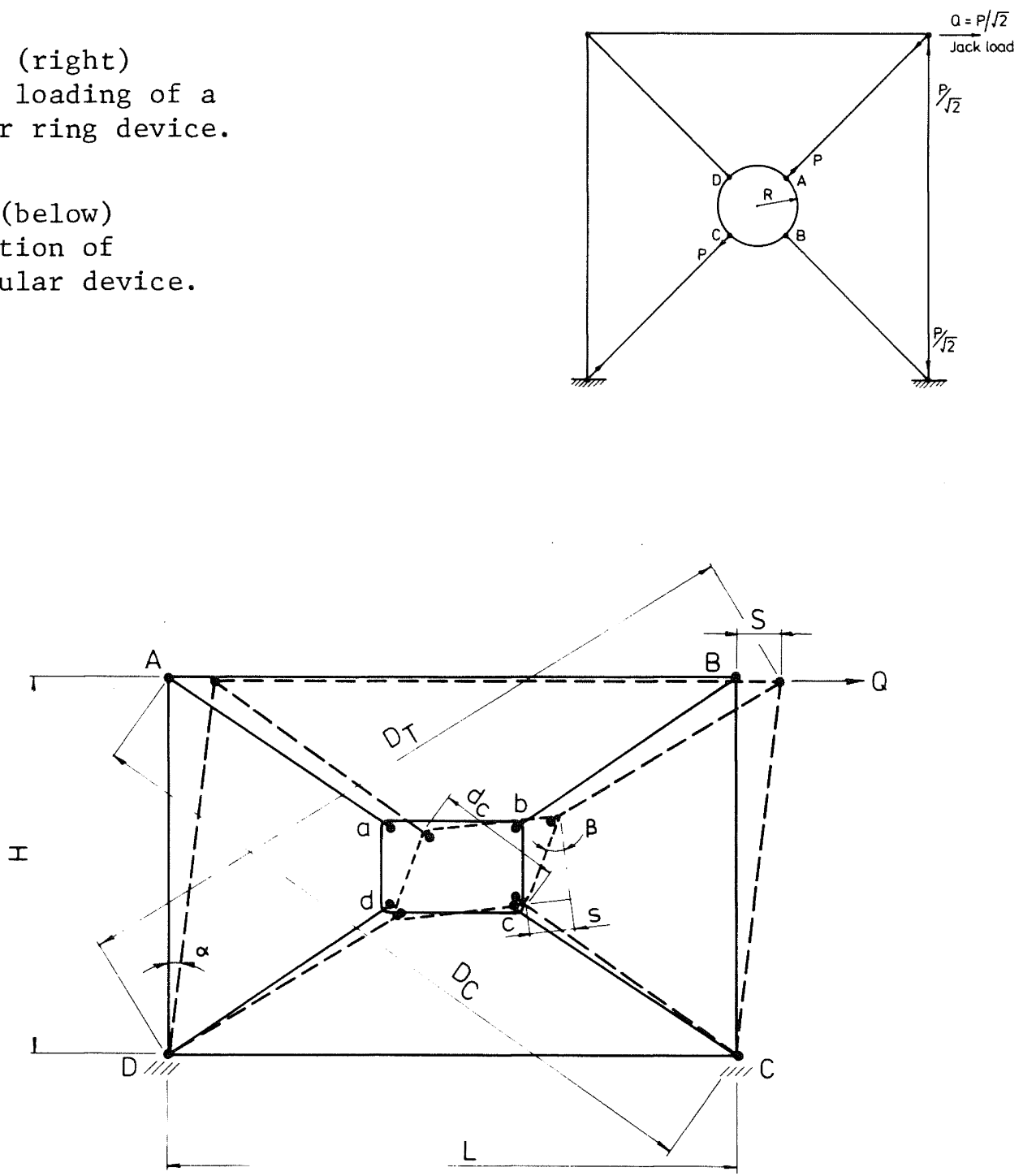
that the curved sections between the loading points would tend to straighten, it was decided nevertheless to investigate a pair of round rings of mean diameter $610 \mathrm{~mm}$, fabricated from $25 \mathrm{~mm}$ round bar tested in a pin-jointed square frame, Fig. 3, of $4 \mathrm{~m}$ side, in a horizontal position, so that slackness was indicated by sagging of the braces and rings. The loading jack had a $200 \mathrm{kN}$ capacity with a stroke of $+150 \mathrm{~mm}$. The rings were formed from bright drawn mild steel, with welds at points of zero moment between the load points. No heat treatment was carried out.

Initially, for small displacements and applied jack load Q, Fig. 4, the loading applied to the ring is the bracing load $P$, where $P=\sqrt{2} Q$, with increasing deformation of the ring, however, tension could develop in the other diagonal as the circle stretched to an ellipse. In practice however, it was found that after about 20 cycles at a stroke of $+100 \mathrm{~mm}$, slackness developed and the rings dropped to the floor. The hysteresis loop (Fig. 5a) indicates the slack by the necking down at the centre. The nuts were then tightened and testing continued. Further tightening was needed periodically until failure occurred in one ring of the pair after about 100 cycles of loading, the speed of loading being up to $1 \mathrm{~Hz}$. The hysteresis loop obtained later in the testing is shown in Fig. 5b, when some stability had developed; the degree of deformation of the ring on failure is shown in Fig. 6 .

\subsection{Ductility Characteristics}

It is shown in Appendix 1 that the bending moment at points $\mathrm{A}$ and $\mathrm{C}$ (Fig. 4) under elastic conditions is greater than that at points $B$ and $D$ for the loading position shown. Thus the ring yields at $A$ and $C$ first with greater deformation then at $B$ and $D$. On reversal of the cycle yield will first occur at $B$ and $D$ and the plastic deformation which has already taken place at $A$ and $C$ will not be corrected. Thus a progressive deformation takes place which caused the device to drop to the floor.

The calculated jack load at a first yield stress of $275 \mathrm{MPa}$ was $6.1 \mathrm{kN}$ (Appendix 1) and the hysteresis loop, Fig. 5, indicates that yield had occurred when this load was reached.

In Appendix 1, the jack force $Q_{D}$ at zero displacement on the hysteresis loops (Fig. 5b) is also calculated in the manner perviously çarried out for steel damping devices $(2,3)$. The value of $Q_{1}$ is used in design work $(4)^{\text {the }}$. The calculation is for a surface strain of $+3 \%$ at the four points of plastic bending, when the plastic yield stress $f$ using the conventional plastic theory of bending is taken as $350 \mathrm{MPa}$, the increase in stress above the yield value of $275 \mathrm{MPa}$ being attributable to work hardening. The geometry of the ring was assumed to be unchanged, i.e. differences would not greatly modify the value of the plastic moments. The calculated value of $Q_{D}$ was $16.9 \mathrm{kN}$. The loops shown in
Fig. 5 show that $Q_{D}$ reached about $20 \mathrm{kN}$ at the maximum stroke of $+140 \mathrm{~mm}$, when the loop shape indicated that the surface strain would have been $\pm 2-3 \%$.

\subsection{Comments}

In conclusion it can be said that the circular device would probably work reasonably well in a practical application for a small number of cycles of loading and this would be assisted if the diagonal rods were pretensioned. It is not, however, to be preferred to the square device tested later.

\section{TESTS ON A SQUARE DEVICE}

\subsection{Test details}

As the $4 \mathrm{~m}$ square floor frame was available from the tests on the circular device, it was decided to proceed with testing a device of square shape, with a view to proceeding to devices of rectangular shape later.

Accordingly, a square device was made up from two bright drawn mild steel rods, $25 \mathrm{~mm}$ diameter, having a side L equal to $610 \mathrm{~mm}$ (Figs. 8-10). Welds were arranged to occur at points of zero bending moment and the corners were bent hot, thus producing a normalising effect similar to that in a hot-rolled steel with a favourable characteristic under repetitive overstrain $(2)$. The saddles used for the circular device; having a radius of curvature of $305 \mathrm{~mm}$ were used unmodified for the square device. This produced an indentation at points NN (Fig. 8) but was not otherwise detrimental. the saddles should be designed to the curvature of the bars at the corner of the square.

A set of hysteresis loops for increasing shear displacement of the frame up to $+142 \mathrm{~mm}$ is shown in Fig. 11. The peaking up of the jack loading. for displacement above $100 \mathrm{~mm}$ is clearly shown, thus indicating a locking-up effect in the device.

\subsection{Ductility characteristics}

Up to the time of first yield at points $a, b, c$ and $d$ (Fig. 7), when deflections are not large, the loading condition is as shown, with the jack load $Q$ producing a force $P$ in a single diagonal, with the other one unloaded. For this condition the elastic moments at the corners of the frame, both for small and large deflections, are all equal (Appendix 1) so that any overstrain occurring at a corner resulting from tension in one diagonal will be reversed when tension develops in the other, ie. there is a stable condition of repetitive overstrain under dynamic loading.

The calculated load $Q$ at first yield, based on a yield stress of $275 \mathrm{MPa}$, is $5.58 \mathrm{kN}$ (Appendix 1), while the hysteresis loops (Fig. Il) indicate that yield had occurred at $6 \mathrm{kN}$, which is fair agreement. 


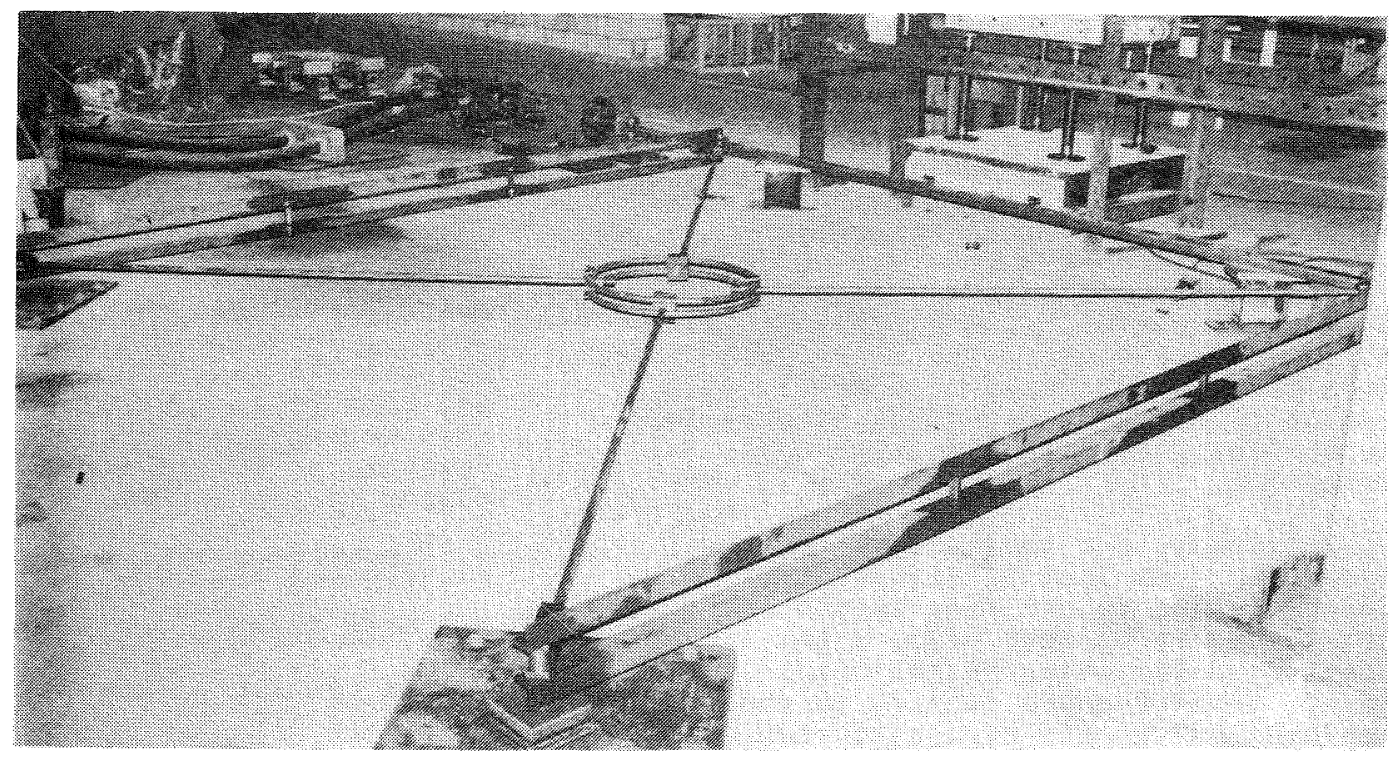

Fig. 3(a) Round device in testing frame

(Dynamic jack in top of picture)

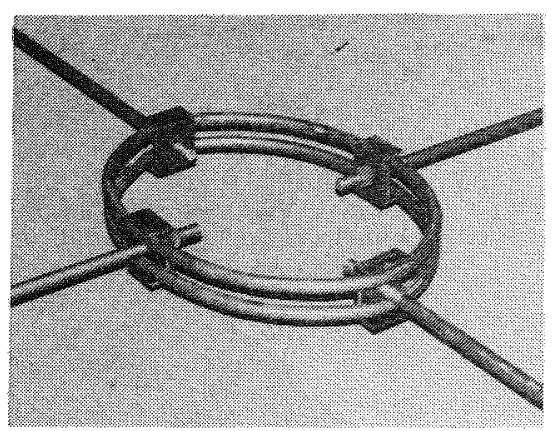

Fig. 3(b)

Elastic loading of ring device, top left to bottom right.

Fig. 6

Failed ring device.

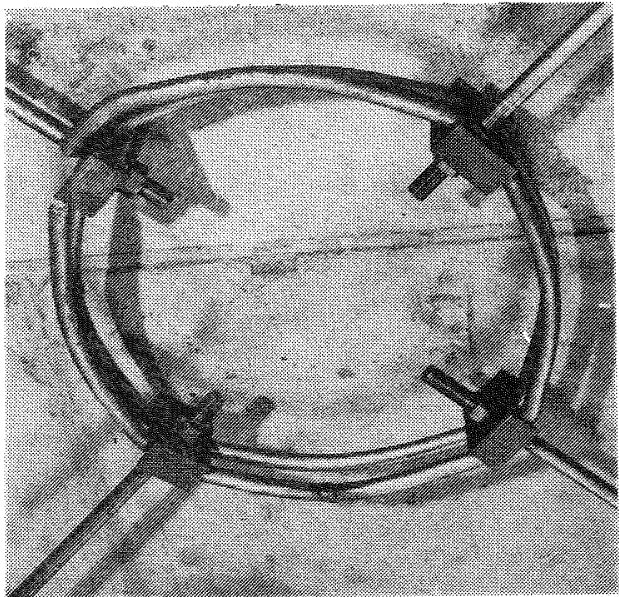


for zero displacement on the hysteresis loops follows that for circular section (Appendix 1) and on the assumption of small deflections, the value was found to be $13.2 \mathrm{kN}$ at a plastic yield stress of $350 \mathrm{MPa}$ and +3\% strain, which compares with a measured value of about $15 \mathrm{kN}+142 \mathrm{~mm}$ of deflection, which is a fair agreement.

The overall ductility factor measured as the ratio of deflection at maximum stroke to deflection at first yield is about 10:1 (Fig. 11).

\subsection{Locking-up effects}

The peaking-up of the hysteresis loops is caused by the change in shape of device from a square to a rhombus (Fig. 2), when two separate effects occur:

(1) The incompatibility of the diagonal lengths of the outer and inner frames with increasing deflection causes self-straining forces which are calculated in Appendix 2. For a particular position of the jack these self-straining forces may be added to those causing plasticity by the principle of superposition. Resolution at the joints of the framework shows that it cannot withstand the selfstraining forces without the additional forces $Q^{\prime}$ and $R$ being imposed on the jack (Fig. 12). In the calculations the incompatibility is taken as a gap $G$ in the shortened diagonal of the main frame for the particular geometry, a force $\mathrm{X}$ on the diagonal being necessary to close the gap by loading all the members by direct forces. The calculations show that the gap is closed mainly from the extensions of the $25 \mathrm{~mm}$ diameter diagonals of the main frame, which have comparatively small cross-sectional areas. Stiffness rates to close the gap $G$ are tabulated in Table A2.2, for increasing displacements and plotted in Fig. 13, which shows the peaking-up effect evident in the measured loops.

(2). The force required to cause plasticity increases as the rhombus contracts in width because of the reduction in moment areas. The rhombus will have zero width at a frame displacement of $520 \mathrm{~mm}$ when the force reouired to cause plasticity will have risen to infinity. The force increases Q" arising from this effect are calculated in Appendix 2 and plotted in Fig. 13 based on an initial value $Q=15 \mathrm{kN}$ taken from Fig. 11 . The rise in force is seen to be a steady one with little peaking up by the time the maximum jack displacement is reached.

The total locking up effect caused by effects 1 and 2 is also plotted in Fig. 13. Evidently the peaking up is mainly caused by the incompatibility in the diagonal lengths, as, at the maximum stroke of $142 \mathrm{~mm}$, effect 1 contributes about $7.2 \mathrm{kN}$, and effect $2,2.2 \mathrm{kN}$. The observed increment in peaking up (Fig. 11) is about $7 \mathrm{kN}$.

It is pointed out in Appendix 2, that the reaction $\mathrm{R}$ at right angles to the jack axis will not be provided in the free condition of a structure under earthquake attack, so locking up will be provided by bending at the joints only, which may lessen the effect. This could be investigated by a model test on a shaking table.

\subsection{Life of the device}

In the tests so far carried out, one set of bars failed after about 200 cycles, mostly at $+100 \mathrm{~mm}$ stroke at frequencies up to $1 \mathrm{~Hz}$. A further set was made up for demonstration purposes and so far this set has not failed after about 150 cycles at various stroke lengths. The nuts in the device were tightened with normal spanner to produce a preload prior to the start of testing and thereafter no further tightening was necessary. The device behaved consistently at fast rates of loading up to about $\mathrm{I} \mathrm{Hz}$ and a cine film was prepared of its performance. Because the life was in excess of 100 cycles it is likely that the maximum value of surface strain was less than $+3 \%$ at $+100 \mathrm{~mm}$ stroke.

\subsection{Comments}

Evidently the device as fabricated would be best worked at a stroke of about $+100 \mathrm{~mm}$, before further deformation causes the loops to peak up. If a design life of 100 cycles is designed for as previously suggested $(2,3)$ then the bar size could be increased slightly for the given geometrical configuration to give a surface strain of about $+3 \%$. Clearly all members should remain elästic within the working load, apart from the yield in bending at the corners of the device. If large deflections are contemplated then the forces in the members arising from secondary effects should be assessed to avoid overstrain in the diagonals.

Further work needs to be done to check the behaviour of rectangular devices and relate bar diameter to size of the device, and stroke, for the required strain of $+3 \%$. For instance, if a short-stroke energy absorber is needed for minimum interstorey drift, then the overall size of the device would need to be reduced to induce overstrain at small deflections of the frame.

\section{CONCLUSIONS}

The tests showed that circular devices were not ideal in that slack developed in the diagonals of the frame. The square device, on the other hand, performed consistently for up to 200 cycles at $1 \mathrm{~Hz}$ for maximum shear deformations of $+142 \mathrm{~mm}$ in the $4 \mathrm{~m}$ frame, with no development of slack. If large deflections are contemplated in parctical applications, then the effect of the self-straining action should be assessed to avoid overstrain in the diagonal members.

As the use of such a device would appear to be an extremely reliable way of ensuring continuing frame action under earthquake attack, the work should be extended to rectangular devices in rectangular frames to establish their behaviour for various ratios of length of the sides; locking-up effects in practical structures should also be investigated.

Further work also needs to be carried 


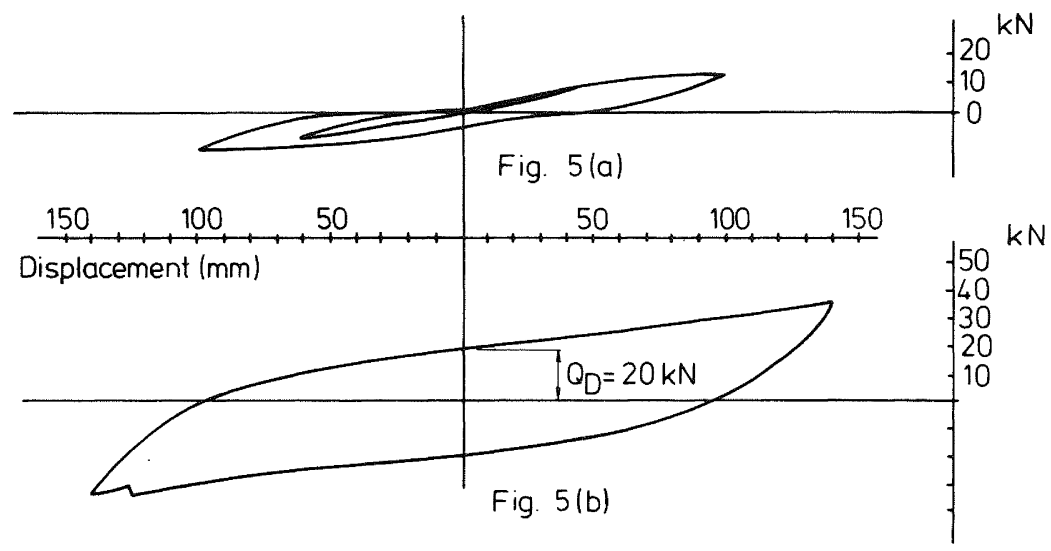

Fig. 5 Hysteresis loops for ring device.

Fig. 7 (atove)

Primary loading of a rectangular device.

Fig. 8 (right)

Details of the square device tested.

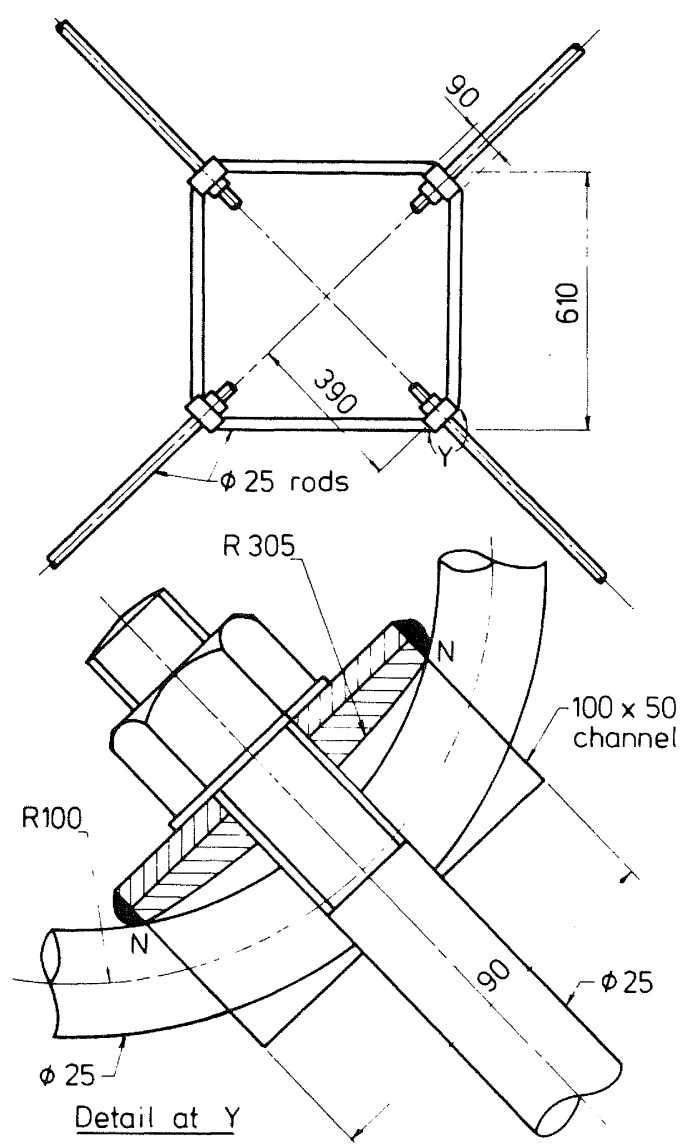


out to establish the relationship between bar diameter, size of rectangle or square and the frame distortion, for a surface strain of $+3 \%$, which will give about 100 cycles tō failure.

Some work should also be carried out on devices formed from flat strip of rectangular cross section, perforated by a single hole at each corner to carry the diagonals, as there may be a simple way of reinforcing the holes to give a reasonable fatique life; welding should be kept away from the zone of high strain however.

\section{REFERENCES}

1. Newmark N.M. and Rosenblueth E., "Fundamentals of Earthquake Engineering", Prentice-Hall Inc. N.J., USA, 1971, pp. 349-50.

2. Tyler R.G. "Tapered Steel Cantilever Energy Absorbers", Bulletin of the New Zealand National Society for Earthquake Engineering, Vol 11 , No. 4, December 1978, pp. 282-294.

3. Tyler R.G., "A Tenacious Base Isolation System Using Round Steel Bars", Bulletin of the New Zealand National Society for Earthquake Engineering, Vol. 11, No. 4, December 1978, pp. 273-281.

4. Park R. and Blakeley R.W.G. "Seismic Design of Bridges" RRU Bulletin No. 43, National Roads Board, Wellington.

\section{ACKNOWLEDGEMENTS}

The author is grateful to consulting engineers David Smith and Robert Henry for originally drawing attention to the advantages of the device, and to

Dr R.I. Skinner for his helpful comments.

\section{NOTATION}

$\mathrm{M}=$ bending moment

$\mathrm{P}=$ load in a diagonal (Figs. 4 and 7 ) to cause bending of the central energy absorbing device

$\mathrm{R}=$ radius of circular device

$\mathrm{d}=$ circular bar diameter

$\mathrm{z}=$ section modulus in elastic bending

$\mathrm{f}_{\mathrm{y}}=\mathrm{yield}$ stress in bending for mild steel taken as $275 \mathrm{MPa}$

$Q \quad=$ load at jack to cause shear deformation of the outer frame

$\mathrm{M}_{\mathrm{y}}=$ moment at first yield of outer fibres in bending

$\theta=$ angle between side 1 of rectangular device and the adjacent diagonal (Fig. 7)

$\mathrm{L}=$ length of main frame

$\mathrm{H}=$ height of main frame

$$
\mathrm{d}
$$

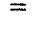

extended diagonal length of the inner frame on the assumption that the whole of the extension of the outer frame diagonal is imposed on the inner, i.e. $\mathrm{d}_{\mathrm{T}}-\mathrm{d}_{\mathrm{O}}=$ $\mathrm{D}_{\mathrm{T}}-\mathrm{D}_{\mathrm{O}}$

$\mathrm{d}_{\mathrm{c}}=$ shortened diagonal length of inner frame for the given value of

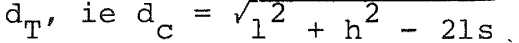

- shear deflection of inner frame for the calculated value of $\mathrm{d}_{\mathrm{T}}$. Evidently $d_{T}=\sqrt{1^{2}+h^{2}+21 s}$ and the value of $s$ is calculated from $d_{\mathrm{T}}-\mathrm{d}_{\mathrm{O}}=\mathrm{D}_{\mathrm{T}}-\mathrm{D}_{\mathrm{O}}$

i.e. $s=\frac{\left(D_{T}-D_{O}+d_{0}\right)^{2}-\left(I^{2}+h^{2}\right)}{2 I}$

G = incompatibility in shortened diagonal lengths between outer and inner rectangles. For a given shear deflection the inner rectangle diagonal length shortens more than the outer i.e.

$G=\left(d_{0}-d_{c}\right)-\left(D_{0}-D_{C}\right)$ $\alpha$

U

Q

$Q_{D}$ angular distortion of outer frame such that $\sin \alpha=\mathrm{S} / \mathrm{H}$

= angular distortion of inner frame such that $\sin \beta=s / h$

= force in shortened diagonal of main frame arising from closure of gap $G$.

$=$ associated tensile forces in links of inner frame to close the gap G, assuming a pin-jointed framework

- corresponding tensile force in extended diagonal

= corresponding compressive force in outer frame members

$=$ jack force

- jack force at zero displacement on the hysteresis loop, used in design work $(4)$

$Q^{\prime}=$ additional jack force required to overcome self-straining action of frame 


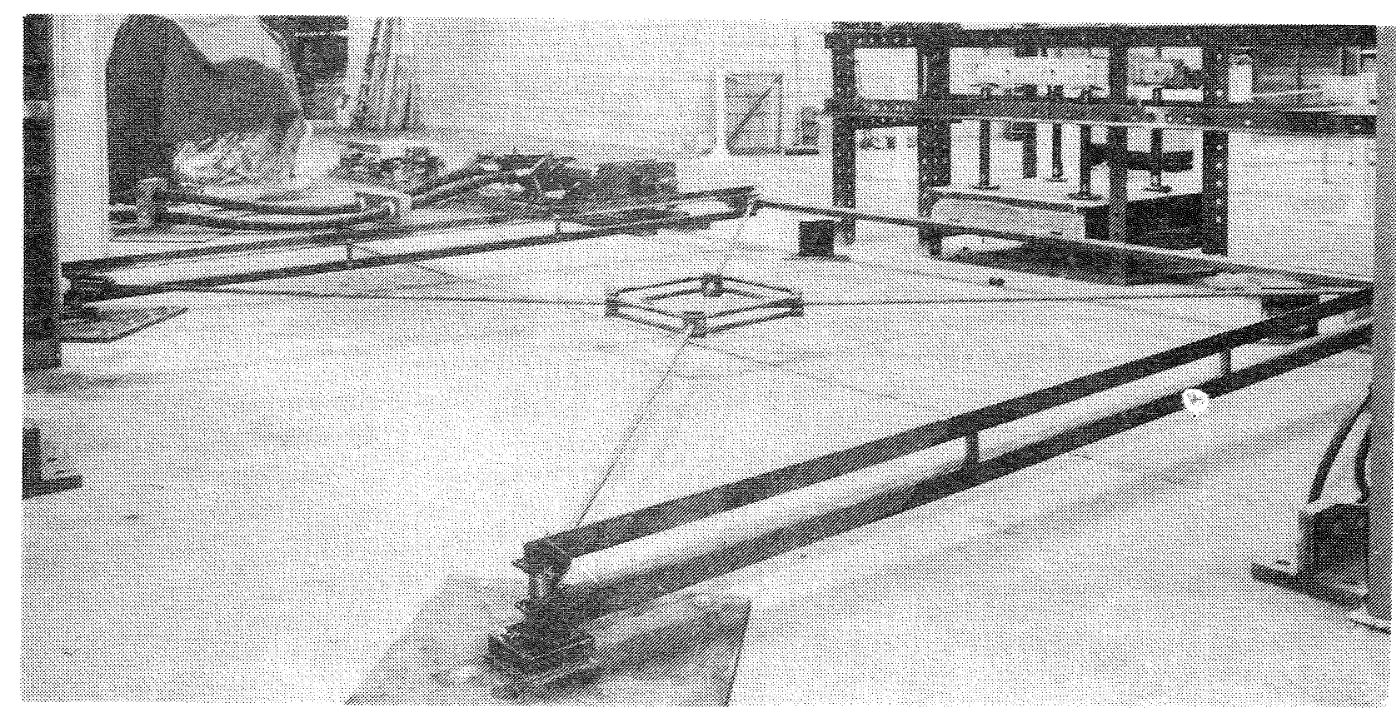

Fig. 9 Square device in test frame.

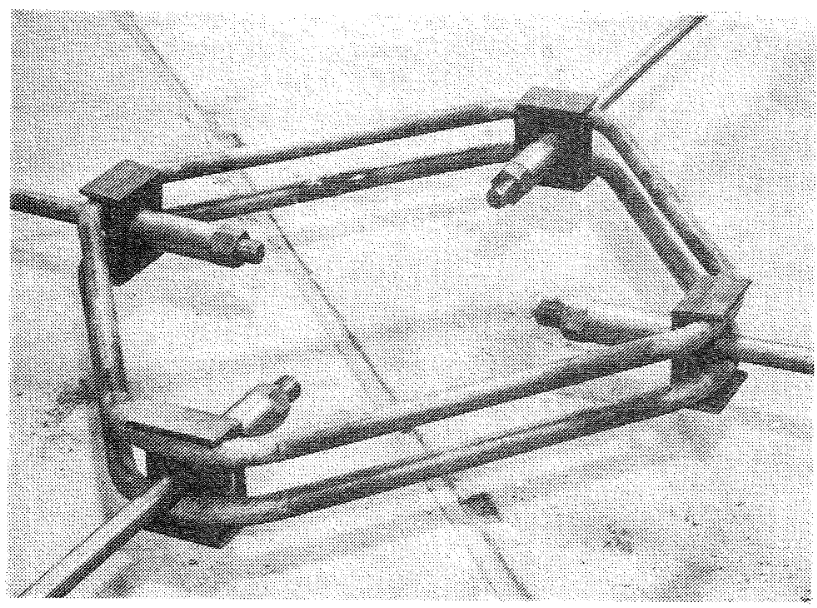

Fig. 10.

Square device deformed in plastic yield.

(a) Load top right to bottom left

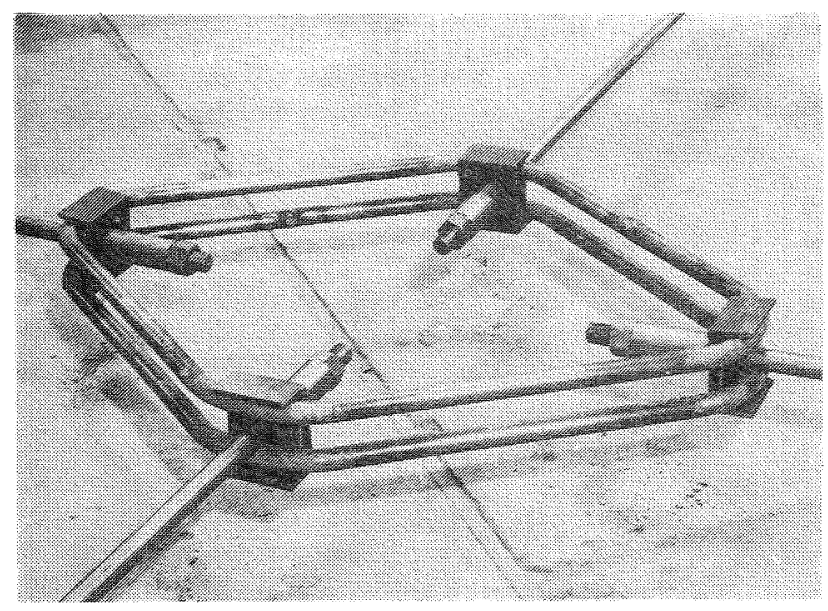

(b) Load left to right. 
Q" = additional jack force allowing for change in shape of the inner rectangle to a parallelogram

$\mathrm{R}=$ reaction at right angles to the axis of the jack carried by the shaft bearings

\section{APPENDIX 1}

\section{DUCTILITY CHARACTERISTICS OF DEVICES}

\subsection{RING DEVICE}

\subsubsection{First yield characteristics}

For the loading condition of tension across a diagonal Fig. 4, the bending moments under elastic conditions are a maximum at the loading points $A$ and $C$ :

$M_{A}=M_{C}=\frac{P R}{\pi}=0.3183 \mathrm{PR}$

for load $P$ and mean radius $R$ of rings, and shear effects neglected.

The moment at non-loaded connection points $B$ and $D$ is given by

$M_{B}=M_{D}=P R(1 / 2-1 / \pi)$ i.e. $0.1817 \mathrm{PR}$

As the ring will yield first at the position of maximum bending moment, i.e. at points $A$ and $C$, this implies $a$ progressive distortion in shape, since loading across the other diagonal at points $B$ and $D$ will first cause yield at $B$ and $D$ and will not entirely correct the plastic deformation which has already taken place at $A$ and $C$.

For two round rods the section modulus $\mathrm{Z}$ is given by

$z=\frac{\pi d^{3}}{16}$ where $d=$ bar diameter $=25 \mathrm{~mm}$

i.e. $z=3.07 \times 10^{-6} \mathrm{~m}^{3}$.

For a yield stress, $f$, taken as $275 \mathrm{MPa}$, this gives a moment at first yield $\mathrm{M}_{\mathrm{y}}$ as:

$M_{y}=f_{y} z=3.07 \times 10^{-6} \times 275 \times 10^{6}=\frac{P R}{\pi}$

at the load point i.e. $P=8.69 \mathrm{kN}$ for $\mathrm{R}=305 \mathrm{~mm}$.

This gives a jack load $Q=8.69 / \sqrt{2}=$ $6.1 \mathrm{kN}$ to cause first yield.

\subsubsection{Force to achieve plasticity}

The value of the force $Q_{D}$ (Fig. 5b) at zero displacement of the hysteresis loops has been used previously in the design of energy dissipating devices $(2,3,4)$. In calculations a plastic yield stress of $350 \mathrm{MPa}$ is used for a section in bending, the rise in stress above the initial yield value of $275 \mathrm{MPa}$ being attributable to work hardening, as evidenced by the fattening of the hysteresis loops with increasing displacement. surface strain is then approximately $+3 \%$ and, for a black mild steel and the number of cycles to failure approximately 100 .
Following the conventional plastic theory, as the stroke is increased hinges will develop at points A, B, C and D (Fig. 4) when the plastic moment $\mathrm{M}_{\mathrm{p}}$ is given by:

$M_{p}=K f_{p}$ where $\mathrm{K}=$ plastic modulus = $\frac{4}{3} r^{3}$ for a round bar

$=5.21 \times 10^{-6} \mathrm{~m}^{3}$ for the bars in the test Also $M_{p}=\frac{P R_{f}}{4}$ for four hinge points, assuming changes in shape can be neglected.

i.e. $P=\frac{4 K f}{R}$, giving $Q_{D}=\frac{2 \sqrt{2} K f}{R}$

substituting $f_{p}=350 \mathrm{MPa}$ gives $Q_{D}=16.9 \mathrm{kN}$.

\subsection{SQUARE DEVICE}

\subsubsection{Yield characteristics}

It may be shown that, neglecting shear effects, the elastic moments at the corners of the rectangular frame shown in Fig. 7 equal and are given by

$\mathrm{M}_{\mathrm{A}}=\mathrm{M}_{\mathrm{B}}=\mathrm{M}_{\mathrm{C}}=\mathrm{M}_{\mathrm{D}}=\frac{\mathrm{P}}{4} \operatorname{lsin} \theta$ for the load $P$ in a diagonal as shown

As plasticity develops and the rectangle contracts to a parallelogram, the moments will be given by the same expression for the reducing value of $\theta$. For a square of side $L$, and small deformations,

$\mathrm{M}_{\mathrm{A}}=\mathrm{M}_{\mathrm{B}}=\mathrm{M}_{\mathrm{C}}=\mathrm{M}_{\mathrm{D}}=\frac{\mathrm{PL}}{4 \sqrt{2}}$

The moment equality at the corners of the device ensures that overstrain in one direction is reversed on the next cycle, i.e. there is no progressive permanent set.

$\mathrm{M}_{\mathrm{Y}}=\mathrm{ZfY}=\frac{\mathrm{PL}}{4 \sqrt{2}} \begin{aligned} & \text { for the moment } \mathrm{M}_{\mathrm{Y}} \\ & \text { at first yield }\end{aligned}$

For fy at first yield $=275 \mathrm{MPa}$

$\mathrm{P}=7.89 \mathrm{kN}$ giving $\mathrm{Q}=7.89 / \sqrt{2}=5.58 \mathrm{kN}$.

\subsubsection{Force to achieve plasticity}

Following the same argument as for the circular device:

$$
\begin{aligned}
M_{P}=K f_{p}=\frac{P L}{4 \sqrt{2}} \quad \begin{array}{l}
\text { with } K=5.21 \\
\text { as before and }
\end{array} \\
\\
\mathrm{f}_{\mathrm{p}}=10^{-6} \mathrm{~m}^{3} \begin{array}{l}
350 \mathrm{MPa} \text { at } \pm 3 \% \\
\text { strain }
\end{array}
\end{aligned}
$$

giving $\mathrm{P}=17.0 \mathrm{kN}$.

This value would need to be increased slightly to allow for the curvature at the corners of the square, as the plastic bending occurred at the points Y (Fig. 8). At these points the dimension $\mathrm{L} / \sqrt{2}=$ $610 / \sqrt{2}=431 \mathrm{~mm}$ is reduced to approximately $390 \mathrm{~mm}$. This would increase $\mathrm{P}$ in the ratio $431 / 390$ i.e. $P=18.8 \mathrm{kN}$. Neglecting secondary effects gives: $Q_{D}=18.8 / \sqrt{2}=13.3 \mathrm{kN}$. 


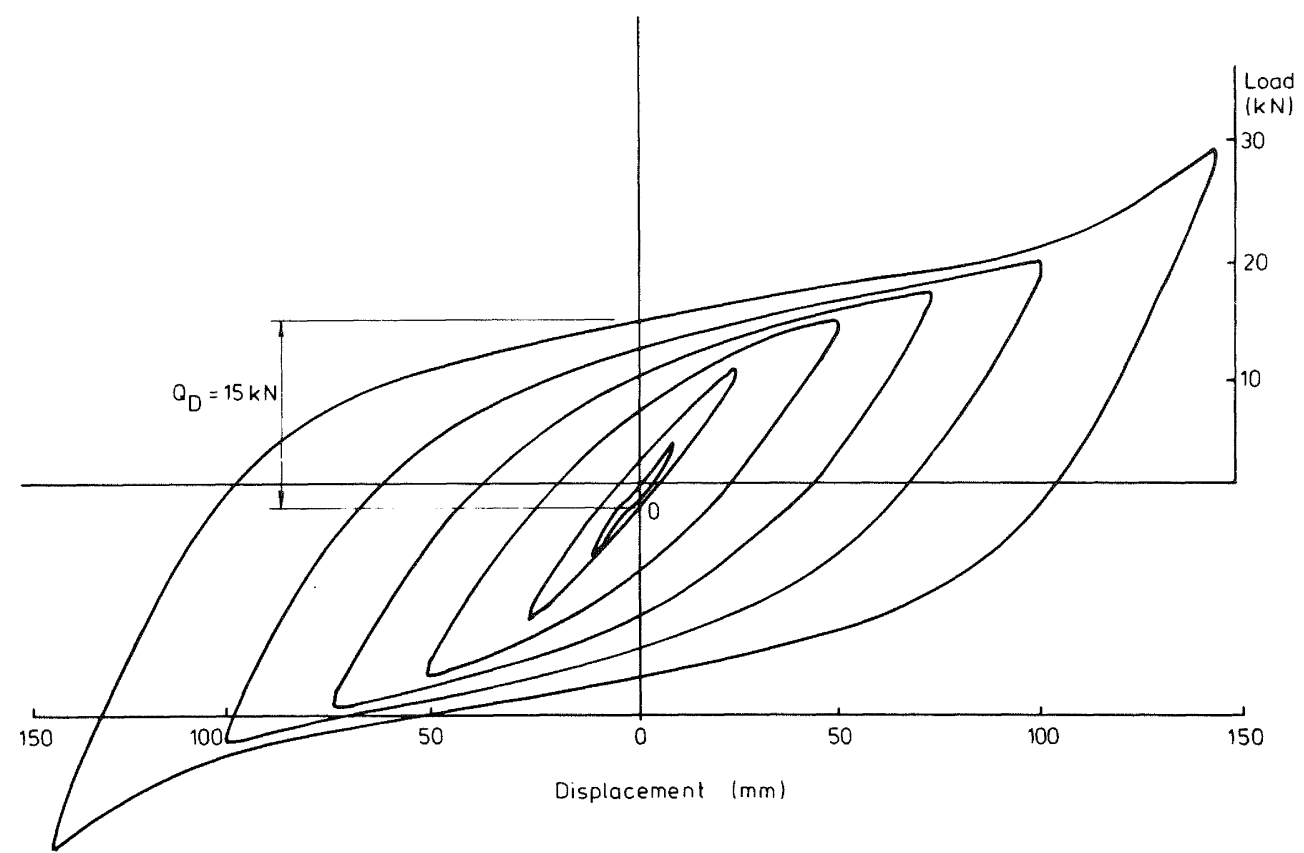

Fig. 11. Hysteresis loops for the square device.

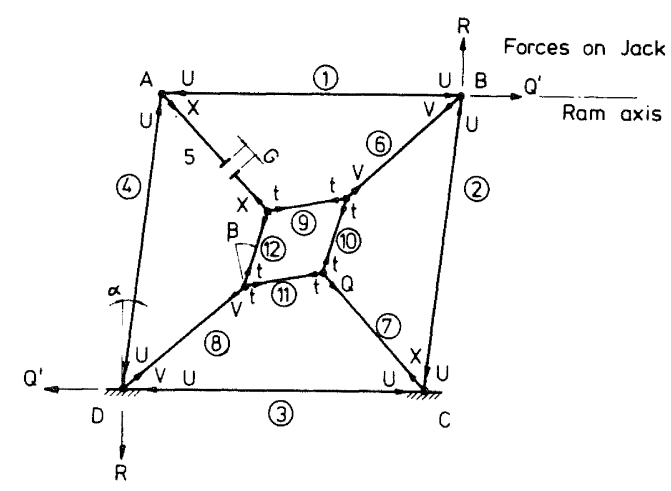

Fig. 12 (left)

Self-straining forces on square frame.

Fig. 13 (below)

Calculated jack forces including secondary effects

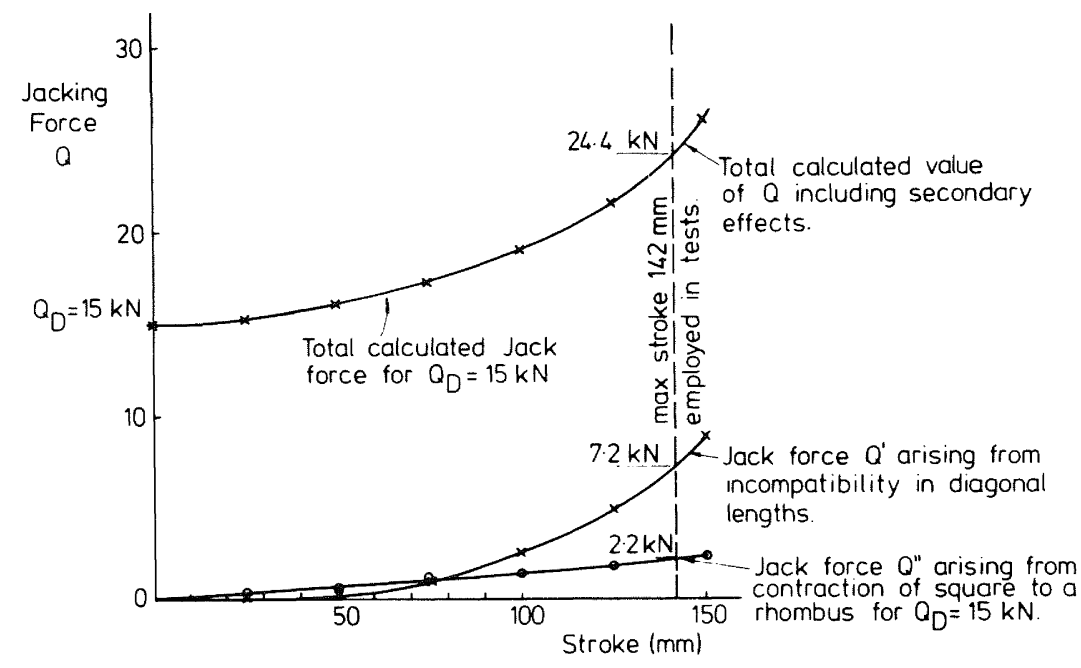




\section{APPENDIX 2}

CALCULATION OF ADDITIONAL JACK FORCES ARISING FROM SECONDARY EFFECTS IN THE SQUARE DEVICE

9.1 Calculation of additional jack force $Q^{\prime}$ arising from incompatibility of diagonal lengths

\subsubsection{General}

On the assumption that the whole of the extension of the diagonal carrying the force V (Fig. 12) is imparted to the diagonal of the inner square, then the length of the opposite diagonal of the inner rectangle shortens more than that of the outer, giving rise to the set of self-straining forces shown, the symmetry being required for overall equilibrium. It is convenient to consider that a gap $G$ in the diagonal member needs to be closed to give the self-straining forces. The external forces $Q^{\prime}$ and $R$, along and at right angles to the jack axis, respectively, are generated, as incompatible forces are induced within the frame.

The geometrical properties of the loaded frame for shear deflection $S$ up to $150 \mathrm{~mm}$ are given in Table A2.1.

In Table A2.2, the force $\mathrm{X}$ required to close the gap $G$, and the corresponding forces $U, t$ and $V$, in other members of the frame are calculated. The stiffness to close the gap $G$ is obtained by applying unit virtual load at $G$ for the pinjointed condition shown in Fig. 12, changes in the bending condition at the four corners of the inner square being neglected, as the strain energy involved would be small and only direct extensions and compressions in the members can accommodate the gap $G$ for a given position of the jack. The greatest extensions are in the four diagonals carrying the forces $X$ and $Y$, which consist of a single $25 \mathrm{~mm}$ dia. rod.

Values of $Q^{\prime}$ and $R$ are calculated at corners $\mathrm{B}$ and $\mathrm{D}$ from the resolved components of the forces $\mathrm{U}$ and $\mathrm{V}$ in Table A2.3. The jack force $Q^{\prime}$ is plotted against shear deflection in Fig. 12. At the maximum stroke of $142 \mathrm{~mm}$ employed in the tests the calculated additional load is $7.2 \mathrm{kN}$.

Since the external force $\mathrm{R}$ at right angles to the jack axis cannot be provided in a practical framework resisting earthquake attack any locking-up action will be provided by bending in the joints of the structure. If the structure is entirely pin-jointed, apart from the bents of the inner rectangle, then it is likely $R$ dissipates in a change of geometry. This aspect should be investigated by shaking a model of an actual structure on a shaking table.

\subsubsection{Values calculated for the $4 \mathrm{~m}$ square frame tested}

$\mathrm{L}=\mathrm{H}=4 \mathrm{~m}$
$\ell=\mathrm{h}=0.61 \mathrm{~m}$
$\mathrm{D}_{\mathrm{O}}=5.6569 \mathrm{~m}$

$$
\begin{aligned}
& D_{T}=\sqrt{32+8 S} \\
& D_{C}=\sqrt{32-8 S} \\
& d_{O}=0.8627 \mathrm{~m} \\
& d_{t}=\sqrt{0.7442-1.22 \mathrm{~s}} \\
& \mathrm{~S}=\left(\left(D_{T}-4.7942\right)^{2}-0.7442\right) / 1.22 \\
& \mathrm{G}=\mathrm{D}_{\mathrm{C}}-\mathrm{d}_{\mathrm{C}}-4.7942 \\
& \alpha=\sin ^{-1}(\mathrm{~S} / 4) \\
& \beta=\sin ^{-1}(\mathrm{~s} / 0.61) \\
& \mathrm{t}=\mathrm{X} / 2 \cos ((90-\beta) / \mathrm{s}) \\
& \mathrm{V}=2 \mathrm{t} \cos ((90-\beta) / 2) \\
& \mathrm{U}=\mathrm{X} / 2 \cos ((90+\alpha) / 2) \\
& \mathrm{Q}^{\prime}=\mathrm{V} \cos ((90-\alpha) / 2)-\mathrm{U}(1+\sin \alpha) \\
& \mathrm{R}=\mathrm{V} \sin ((90-\alpha) / 2)-\mathrm{U} \cos \alpha
\end{aligned}
$$

9.2 Calculation of additional jack force $Q^{\prime \prime}$ arising from contraction of the square

Values of the diagonal length $d$ of the absorber as the shear deformation of the frame increases are given in column 2 of Table A2.4. The force required to cause plasticity will be inversely proportional to $\mathrm{d}_{\mathrm{c}}$ and in column 3 the percentage increase is given. In column 4 the values of the jacking force $Q$ " are given based on an initial value of $Q=15 \mathrm{kN}$ at zero deflection. These values are plotted in Fig. 13. As $\mathrm{d}_{\mathrm{C}}=0$ when $\mathrm{S}=520 \mathrm{~mm}, \mathrm{Q}^{\prime}$ rises to $\mathrm{C}$ infinity at that value. From Fig. 13 at the maximum value of shear deflection used in the tests, i.e. $\mathrm{S}=142 \mathrm{~mm}$, the value of $Q^{\prime \prime}$ is approximately $2.2 \mathrm{kN}$.

\subsection{Calculation of total force Q based on a value of $Q_{\mathrm{D}}=15 \mathrm{kN}$}

Taking the experimental value of $Q_{D}=15 \mathrm{kN}$ then the total jack force $Q$ for a given displacement will be given by $Q=Q^{\prime}+Q^{\prime \prime}$ as in column 6 of Table A2.4. This is shown plotted in Fig. 13. The total value of $Q$ at the peak experimental displacement $\mathrm{S}=142 \mathrm{~mm}$ is shown to be $24.4 \mathrm{kN}$, with a peaking up similar from that on the experimental loop (Fig. 11). The peak experimental value was about $29.5 \mathrm{kN}$ which compares well with the calculated value of $24.4 \mathrm{kN}$ bearing in mind that, with no secondary effects, there would be a normal rise in the force value on the hysteresis loop caused by work hardening. 
TABLE A2.I

Geometrical properties of frame under shear deformation

\begin{tabular}{|c|c|c|c|c|c|c|c|}
\hline $\begin{array}{l}1 \\
\text { Shear } \\
\text { deflection } \\
\text { of frame } \\
\text { S } \\
(\mathrm{mm})\end{array}$ & $\begin{array}{c}2 \\
\text { Frame } \\
\text { Diagonal } \\
\text { length } \\
\mathrm{D}_{\mathrm{T}} \\
(\mathrm{m})^{\mathrm{T}}\end{array}$ & $\begin{array}{c}3 \\
\text { Frame } \\
\text { Diagonal } \\
\text { length } \\
\text { D } \\
\text { (m) }\end{array}$ & $\begin{array}{c}4 \\
\text { Shear } \\
\text { deflection } \\
\text { of absorber } \\
\text { s } \\
(\mathrm{mm})\end{array}$ & $\begin{array}{l}5 \\
\text { Absorber } \\
\text { Diagonal } \\
\text { length } \\
\text { d } \\
(\mathrm{mm})^{\mathrm{C}}\end{array}$ & $\begin{array}{c}6 \\
\text { Incompatibility } \\
(\mathrm{mm})\end{array}$ & $\begin{array}{c}7 \\
\text { Angular } \\
\text { distortion } \\
\text { of frame } \\
\alpha\end{array}$ & $\begin{array}{c}8 \\
\text { Angular } \\
\text { distortion } \\
\text { of absorber } \\
\beta^{\circ}\end{array}$ \\
\hline $\begin{array}{r}0 \\
25 \\
50 \\
75 \\
100 \\
125 \\
150\end{array}$ & $\begin{array}{l}5.6569 \\
5.6745 \\
5.6921 \\
5.7089 \\
5.7271 \\
5.7446 \\
5.7619\end{array}$ & $\begin{array}{l}5.6569 \\
5.6391 \\
5.6214 \\
5.6043 \\
5.5857 \\
5.5678 \\
5.5498\end{array}$ & $\begin{array}{c}0 \\
25.19 \\
50.84 \\
75.80 \\
103.36 \\
130.38 \\
157.58\end{array}$ & $\begin{array}{l}862.67 \\
844.67 \\
825.94 \\
807.29 \\
786.19 \\
764.94 \\
742.93\end{array}$ & $\begin{array}{r}0 \\
0.23 \\
1.26 \\
2.81 \\
5.31 \\
8.66 \\
12.70\end{array}$ & $\begin{array}{l}0 \\
0.3581 \\
0.7162 \\
1.0744 \\
1.4324 \\
1.7908 \\
2.1491\end{array}$ & $\begin{array}{r}0 \\
2.367 \\
4.781 \\
7.138 \\
9.755 \\
12.342 \\
14.971\end{array}$ \\
\hline
\end{tabular}

TABLE A2. 3

Calculation of jack forces $Q^{\prime}$ and to close the gap $G$

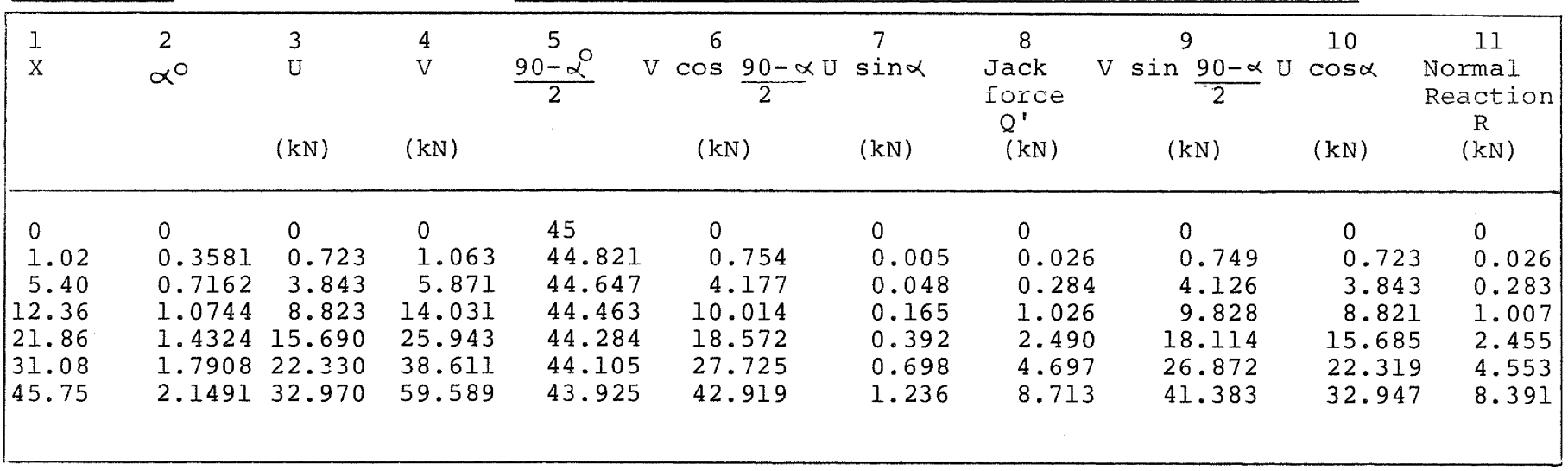

TABLE A2.2

Calculation of forces in members to close the gap $G$

\begin{tabular}{|c|c|c|c|c|c|c|}
\hline $\begin{array}{c}\mathrm{S} \\
(\mathrm{mm})\end{array}$ & $\mathrm{U} / \mathrm{X}$ & $t / x$ & $V / X$ & $\begin{array}{c}\text { Stiffness } \\
X / \mathrm{G} \\
\mathrm{kN} / \mathrm{mm}\end{array}$ & $\begin{array}{c}\mathrm{G} \\
(\mathrm{mm})\end{array}$ & $\begin{array}{c}\mathrm{X} \\
(\mathrm{kN})\end{array}$ \\
\hline $\begin{array}{r}0 \\
25 \\
50 \\
75 \\
100 \\
125 \\
150\end{array}$ & $\begin{array}{l}.7071 \\
.8093 \\
.7116 \\
.7138 \\
.7161 \\
.7184 \\
.7207\end{array}$ & $\begin{array}{l}.7071 \\
.7220 \\
.7386 \\
.7564 \\
.7760 \\
.7974 \\
.8211\end{array}$ & $\begin{array}{l}1 \\
1.0420 \\
1.0872 \\
1.1352 \\
1.1868 \\
1.2423 \\
1.3025\end{array}$ & $\begin{array}{l}4.808 \\
4.619 \\
4.427 \\
4.233 \\
4.033 \\
3.828 \\
3.625\end{array}$ & $\begin{array}{r}0 \\
0.22 \\
1.22 \\
2.92 \\
5.42 \\
8.12 \\
12.62\end{array}$ & $\begin{array}{r}0 \\
1.02 \\
5.40 \\
12.36 \\
21.86 \\
31.08 \\
45.75\end{array}$ \\
\hline
\end{tabular}

TABLE A2.4 Calculation of total jack force required allowing for secondary effects

\begin{tabular}{|c|c|c|c|c|c|}
\hline $\begin{array}{r}1 \\
\mathrm{~S} \\
(\mathrm{~mm})\end{array}$ & $\begin{array}{l}2 \\
\mathrm{~d}_{\mathrm{C}} \\
(\mathrm{mm})\end{array}$ & $\begin{array}{c}3 \\
\text { Force } \\
\text { increase for } \\
\text { plasticity } \\
\frac{\circ}{0}\end{array}$ & $\begin{array}{c}4 \\
Q^{"} \\
(\mathrm{kN}) \\
\text { for } \\
\mathrm{Q}_{\mathrm{D}}=15 \\
(\mathrm{kN})\end{array}$ & $\begin{array}{c}5 \\
Q^{\prime} \\
(\mathrm{kN}) \\
\text { from } \\
\text { Table } \mathrm{A} 2.3\end{array}$ & $\begin{array}{c}6 \\
\operatorname{Total} \\
Q \\
=Q^{\prime+Q}+Q_{D} \\
(k N)\end{array}$ \\
\hline $\begin{array}{r}0 \\
25 \\
50 \\
75 \\
100 \\
125 \\
150\end{array}$ & $\begin{array}{l}863 \\
845 \\
826 \\
806 \\
786 \\
766 \\
743\end{array}$ & $\begin{array}{r}0 \\
2.2 \\
4.5 \\
7.0 \\
9.8 \\
12.7 \\
16.2\end{array}$ & $\begin{array}{l}0 \\
0.3 \\
0.7 \\
1.1 \\
1.5 \\
1.9 \\
2.4\end{array}$ & $\begin{array}{l}0 \\
0 \\
0.3 \\
1.0 \\
2.5 \\
4.7 \\
8.7\end{array}$ & $\begin{array}{l}15.0 \\
15.3 \\
16.0 \\
17.1 \\
19.0 \\
21.6 \\
26.1\end{array}$ \\
\hline
\end{tabular}

